\title{
Acceptance of a smartphone navigation application by hospital patients and visitors: the role of gender, age, and education
}

\author{
JAN ŽENKA ${ }^{1}$, JAN MACHÁČEK ${ }^{1}$, LudĚK KRTIČKA ${ }^{1}$, PAvel MICHNA² and PAvel KOŘÍZEK ${ }^{3}$
}

\begin{abstract}
This paper analyses the acceptance of a smartphone navigation app in a hospital among its patients/visitors. We tested the effects of socio-demographic factors (gender, age, and education) on technology acceptance and on perceived difficulties with wayfinding in the hospital complex. The empirical research is based on a survey among 928 patients/visitors of the Vítkovice Hospital in Ostrava, Czechia. We found that the acceptance of smart navigation increases with the level of education and decreases with age. No significant gender differences were observed.
\end{abstract}

Keywords: technology acceptance, hospital, gender, age, education, smartphone navigation

Received March 2021, accepted May 2021

\section{Introduction}

There are several reasons why wayfinding in hospitals requires systematic research. Many authors document increasing difficulties with wayfinding in large complex buildings, including hospitals (HöLscher, C. et al. 2006; Anagnostopoulos, G.G. et al. 2017). Patients and visitors of healthcare facilities may face considerable anxiety and stress resulting from navigational issues (Wolstenholme, D. et al. 2010; Devlin, A.S. 2014). Staff members also face difficulties in wayfinding and are often asked for advice by hospital patients and visitors, which may negatively affect their productivity (Mollerup, P. 2009). Navigational needs and strategies, spatial and wayfinding skills are associated with gender (LAwTON, C.A. 2001), age (Harris, M.A. and Wolberts, T. 2014), education (ŽENKA, J. et al. 2021), culture (Davies, C. and Pederson, E. 2001), and, most importantly, mental and health (dis) abilities (Souza, R.F. and Martins, L.B. 2019). Wayfinding in a large complex building such as a hospital is also context-dependent, being affected by the specificities and history of the building, its architectural setting, urban design factors, and the connection of the place to other parts of the city.

Dealing with the increasing complexity of large buildings requires the adoption of technology-based smart solutions to complement traditional navigational issues, such as maps, plans, signs, arrows, or colour signs. Recently, one of the most progressive solutions to navigational issues has been the adoption of smartphone navigation applications for indoor positioning. The development and/or implementation of a useful smartphone navigation app should be based on a survey of navigational needs among the potential users.

\footnotetext{
${ }^{1}$ Department of Social Geography and Regional Development, Faculty of Science, University of Ostrava, Chitntussiho 10, 71000 Ostrava, Czech Republic. E-mails: jan.zenka@osu.cz, jan.machacek@osu.cz, ludek.krticka@osu.cz

2 AGEL a. s., Jungmannova 28/17, Nové Město, 11000 Praha 1, Czech Republic.

${ }^{3}$ AGEL Research and Training Institute, Mathonova 291/1, Krasice, 79604 Prostějov, Czech Republic.
} 
Thus, our first research question is to what extent the respondents (patients and visitors) accept smartphone navigation apps and use them for orientation in the hospital. The second research question is to what extent are the navigational preferences of hospital patients/visitors associated with socio-demographic factors: gender, age, and education. Finally, we also ask to what extent are the perceived wayfinding difficulties associated with gender, age, education, and location. Do men and women, younger and elderly people, or less educated and more educated people perceive the same hospital departments as difficult to find, or are there any significant differences? Based on these answers, we aim to provide specific recommendations for designing hospital navigation systems that will be based not only on theoretical arguments but also on the empirical identification of the navigational preferences and needs of hospital patients and visitors.

The empirical analysis in this paper draws on a case study of the Vítkovice Hospital (official name: 'Nemocnice AGEL, OstravaVítkovice') in the city of Ostrava (Czechia). With an area of 4.2 ha and 11 pavilions, it is rather a small hospital. Therefore, patients and visitors are not in urgent need of a more technologically advanced navigational system, allowing them to cope with the complexity of the site (see ŽENKA, J. et al. 2021 for a more detailed description of the navigational system in the hospital). Nevertheless, our empirical research (see section 'Results') revealed that even in a hospital complex of this size, there are frequent issues with wayfinding among both patients and visitors.

We conducted 928 questionnaires with hospital patients and visitors, focusing on their perception of the current navigational system in the hospital, on the preferences of various types of navigational cues, and, most importantly, on their acceptance of a smart navigation application. While the existing literature on wayfinding in hospitals is abundant, we would like to contribute by connecting two different avenues of research: a) Theoretical papers testing the effects of gender, age, and education on wayfinding (LAwTON, C.A. 2001; IARIA, G. et al. 2009; AnActa, V.J.A. and Schwering, A. 2010; Silber-VArod, V. et al. 2019; Mendez-Lopez, M. et al. 2020);

b) Applied studies analysing the technological or management aspects of hospital navigation systems (BALATA, J. et al. 2013; Calderoni, L. et al. 2015; Anagnostopoulos, G.G. et al. 2017).

In the next section, we discuss the determinants of people's willingness to use smart navigational applications, focusing on the effects of age, gender, education, and their possible interactions. The third section provides the characteristics of data sources and methods, while the fourth presents the selected results of statistical tests. In the fifth section, we compare our empirical findings with those of other authors. The sixth section concludes.

\section{Gender, age, education, and their effects on technology acceptance}

The primary dependent variable in our research is technology acceptance: the propensity of patients/visitors to use a smart navigation app in the hospital. The traditional explanation of the adoption and usage of telecommunication technologies is provided by the digital divide model (RICE, R.E. and KatZ, J.E. 2003), based on the effects of gender, age, and education. The adoption of technology improves with the level of education and declines with increasing age. Younger people and people with a higher level of formal education should adopt technology faster than older people and people with a lower level of education. Older individuals tend to face greater difficulties in processing new or complex information, which affects their use of modern technologies (Custodio, R. et al. 1986; Morris, M.G. et al. 2005). This problem can be attributed to a decline in cognitive and memory skills related to the ageing process (Posner, R.A. 1997; Venkatesh, V. et al. 2012). These authors contend that the adoption and 
use of mobile internet technology lessens with age, as older men in particular rely more on established habits than on mobile internet technology. Harwood, J. (2007) argued that different age groups have different behavioural patterns in mobile technology use.

Men are generally assumed to adopt technology faster than women, but this applies only in the early phase of the adoption of the technology. Several authors have documented small gender differences in the ability and willingness to use smart navigation technologies (HwAng, K.H. et al. 2016; Silber-VARod, V. et al. 2019; ŽENKA, J. et al. 2021). Custodio, R. et al. (1986) argue that less-educated users may be financially constrained in the use of modern technologies. Educated young users, on the other hand, are increasingly using e-maps and other mobile apps because they are encouraged to do so in school and when using social networks (LAPON, L. et al. 2020). Nevertheless, interactions between gender and education or gender and age may affect patterns of individual willingness to use technology more significantly than the isolated effects of these sociodemographic variables. To capture these associations, we discuss briefly two sophisticated theories that are useful for the explanation of individual technology acceptance.

In general terms, our point of departure is the theory of planned behaviour (TPB) (AJzen, I. 1991). This psychological theory explains an individual intention to perform behaviour by the effects of three variables: attitude toward a behaviour, subjective norm, and perceived behavioural control (PBC). The attitude toward using technology is defined as a respondent's effective evaluation of the benefits and costs of using the technology (Morris, M.G. et al. 2005); in our paper it is the perceived usefulness of the smart navigation app. Subjective norm is 'the perceived social pressure to perform or not to perform the behaviour' (AJZEN, I. 1991, 188): e.g. public/marketing pressure and the recommendations of 'important people in my life' to use the smart navigation app in the hospital. PBC is related to the availability of skills, resources, opportunities, and their importance in the achievement of the outcome, defined as the 'perceived ease or difficulty of performing the behaviour' (AJzEN, I. 1991, 188). In this case, it covers financial costs, necessary knowledge to manage the smart navigation app, own control over the app, and its compatibility with other relevant software systems and applications. For our research, we employ also the unified theory of technology adoption (UTAUT) in the second version (VENKATESH, V. et al. 2012; - see also VenKATESH, V. et al. 2003 for the first version), applying the principles of TPB to explain individual intention (not) to use technology.

According to this theory, gender and age moderate the relationship between the explanatory variables (performance expectancy, effort expectancy, social influence, facilitating conditions, price value, hedonic motivation, and habit) and the intention to use a new technology (Venkatesh, V. et al. 2012). Gender differences in the importance of facilitating conditions (training, support) become more distinctive with age (MorRIs, M.G. et al. 2005). Older women place more emphasis on facilitating conditions and effort expectancy (ease of consumer's use of the technology) when adopting a new technology, especially in the early stages of adoption. They are more determined to use these technologies when they become aware that these technologies will make their lives easier (HwANG, K.H. et al. 2016). Men, on the other hand, tend to rely less on facilitation conditions and more on performance expectancy (perceived benefits associated with the use of technology) when considering the use of a new technology (Morris, M.G. et al. 2005). This can also be partly explained by the effect of gender roles in society, where men tend to be more task oriented (Lynnot, P.P. and McCandless, J. 2000). For users with less experience of modern technologies, the effect of age and gender on their technology acceptance will be more significant than for more experienced users.

Finally, we turn to the geographical aspects of technology acceptance in hospitals, considering the role of gender, age, and education. 
To our best knowledge, no theoretical framework linking technology acceptance and spatial factors exists. The intention to use a smart navigation app should be higher in large, complex, and uniformly designed buildings. The absence or low visibility of landmarks and other navigational cues (arrows, maps, colour strips) is expected to increase technology acceptance. Women should be more sensitive to these issues for several reasons:

a) they exhibit higher levels of uncertainty and spatial anxiety than men (LAwTON, C.A. 1994; Mendez-Lopez, M. et al. 2020);

b) women perform slightly worse in spatial orientation in the real environment than men (Coluccia, E. and Louse, G. 2004);

c) women rely on a 'route strategy' in their navigation (LAwTON, C.A. 1994; LiAO, H. and Dong, W. 2017), following the sequence of landmarks and left-right turns, while men prefer cardinal directions (North-South), global reference points (central square, airport, sun in the sky) and Euclidean distances (see also LAwTON, C.A. et al. 1996, or ŽENKA, J. et al. 2021).

Therefore, men are expected to evaluate orientation in the hospital complex as a whole, while women may view some buildings/parts of the complex as very easy and the others as very difficult to find. They should be more polarized in their evaluations of particular buildings and their perceived wayfinding difficulties should be more spatially concentrated at the level of buildings in the hospital complex. Correspondingly, the same differences are expected between younger and older people and between people with elementary, secondary, and tertiary education. With increasing age, the spatial abilities of elderly people deteriorate (Newman, M.C. and Kaszniak, A.W. 2000; Devlin, A.S. 2014), and elderly people rely more on the route strategy than younger people (RoDGERs, M.K. et al. 2012). Less educated people show lower orientation scores (ULRICH, S. et al. 2019) and are likely to follow a route strategy, while empirical evidence for the latter is missing. To sum up, we expect that the acceptance of smart navigation apps will differ among par- ticular hospital pavilions and departments, depending on the perceived difficulties of finding these places. This relationship will be stronger among women and among elderly or less educated people. In the next section we describe the data and methods used to test these relationships.

\section{Data and methods}

To collect data from our respondents (patients and visitors of the hospital), we used structured questionnaires in the paper form. Respondents were asked to evaluate the hospital navigation system and assess their acceptance of a smartphone application for navigation in the Vítkovice Hospital. However, smartphone applications were not highlighted in the questionnaire, as we did not want to influence the decisions of the respondents. Focus groups, including doctors, nurses, and other medical and technical staff, were employed to improve the design of the survey (based on the approach of BROwN, M. et al. 2016).

In the first step, we piloted the survey among 100 respondents to check the adequacy, relevance, and comprehensibility of the questions. Based on the results, we adapted or reformulated several questions to improve their comprehensibility. Next, 4,000 questionnaires were distributed to the selected departments of the Vitkovice Hospital (according to the mean weakly number of patients) between $26^{\text {th }}$ June and $3^{\text {rd }}$ July 2019 (a working week). The response rate was 23.2 per cent, as we collected 928 filled questionnaires. Respondents answered 13 questions about their previous experience with wayfinding in the hospital/department, their willingness to use the smartphone application, or traditional navigational cues. In this paper, we analyse six selected questions (Table 1). Some questions were not answered by all respondents or were answered incorrectly. Therefore, the number of valid responses $(\mathrm{N})$ among the various questions varied slightly. 
Table 1. Variables employed in the statistical analysis

\begin{tabular}{|c|c|c|c|}
\hline Variable name & Type & Scale & Description \\
\hline Wayfinding difficulties & \multirow[b]{2}{*}{ dependent } & ordinal & $\begin{array}{l}\text { Is it easy to find this department for the new comers? } \\
1=\text { easy; } 2=\text { some difficulties; } 3=\text { difficult. }\end{array}$ \\
\hline SmartApp acceptance & & \multirow[t]{2}{*}{ binary } & $\begin{array}{l}\text { Would you use a smartphone for navigation in the } \\
\text { hospital? } \\
1=\text { yes; } 2 \text { = no. }\end{array}$ \\
\hline Smartphone ownership & descriptive & & $\begin{array}{l}\text { Do you have a smartphone? } \\
1=\text { yes; } 0=\text { no. }\end{array}$ \\
\hline Location & \multirow{4}{*}{ explanatory } & nominal & $\begin{array}{l}\text { Hospital pavilion, where the respondent filled the } \\
\text { questionnaire and evaluated the difficulties with } \\
\text { finding a way to the pavilion. }\end{array}$ \\
\hline Gender & & binary & $0=$ male; $1=$ female \\
\hline Age & & \multirow[b]{2}{*}{ ordinal } & $1=0-20 ; 2=21-40 ; 3=41-60 ; 4=$ more than 60 years \\
\hline Education & & & $\begin{array}{l}1=\text { no or elementary; } \\
2=\text { secondary; } 3=\text { tertiary }\end{array}$ \\
\hline
\end{tabular}

Source: ŽEnKA, J. et al. 2021; own survey.

To measure the spatial concentration of perceived wayfinding difficulties in the hospital complex (based on the answers of respondents to questions concerning the difficulty of finding a hospital department), we employed the Herfindahl-Hirschmann index, constructed as:

$$
H H I=\sum_{i=1}^{\mathrm{n}} s_{i}^{2}
$$

where $s_{i}$ is the share of answers (that the hospital department in that pavilion was difficult to find or to be found with some difficulty), we collected in pavilion I in the total number of answers in the hospital complex.

Apart from basic descriptive statistics, we used two kinds of statistical tests: Crammer $\mathrm{V}$ and the binary logistic regression model. In the first step, two dependent variables (SmartApp acceptance and Wayfinding difficulties) were associated with the explanatory variable Location to test potential geographical effects on technology acceptance and orientation in the hospital complex. To capture the potential effects of gender, age and education, statistical tests were conducted separately for men and women, people in different age groups, and people with elementary, secondary and tertiary education.

In the next step, we focused on the single most important dependent variable: SmartApp acceptance. A binary logistic regression model has been constructed, with gender, age, education, and the interaction between gender and age as explanatory variables (see the next section for details and interpretation).

\section{Results}

Let us start by presenting the selected descriptive statistics of the sample (Figure 1). Newcomers and people visiting the hospital after a long time accounted for 44.1 per cent of all respondents. Not surprisingly, the major groups in the sample were middle-aged people (41-60 years old) and the elderly (over 60 years old) who visit the hospital department regularly or often. These respondents may be

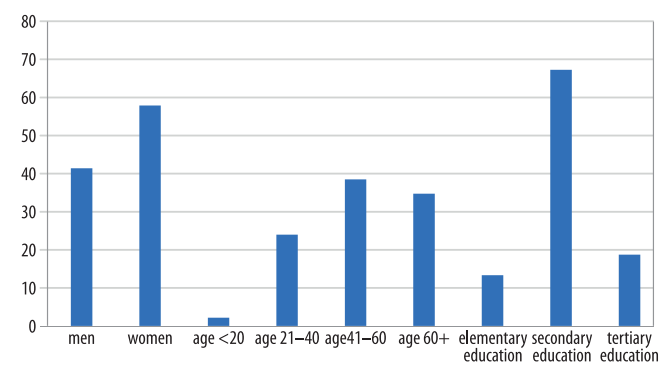

Fig. 1. Basic descriptive statistics of the sample. Source: Author's own survey. 
more reluctant to use smartphone applications and changes in the navigational system of the hospital. While two-thirds of respondents answered that wayfinding in the Vitkovice Hospital is easy, many of them $(31.2 \%)$ are regular visitors. Correspondingly, this is also one of the reasons why only 35.4 per cent of respondents affirmed that the navigational system in the hospital needed to be improved (14.1\% 'yes', and 21.3\% 'rather yes'). Despite the high share of regular visitors and the elderly, 68.9 per cent of respondents are willing to use smartphone navigation in the hospital.

The survey (see ŽEnkA, J. et al. 2021 for details) showed that almost 60 per cent of respondents had their smartphones in the hospital (Figure 2). Nevertheless, only 46.8 per cent of them would definitely use their smartphone for navigation in the hospital and another 31.3 per cent would use it only if they got lost. While the ownership of a smartphone is higher among women, men are slightly more willing to use it for navigation. In line with our expectations, the willingness to use a smart navigational app was the lowest in the group of $60+$ people (below $20 \%$ ) and highest in the group 21-40 (young respondents below 20 were underrepresent-

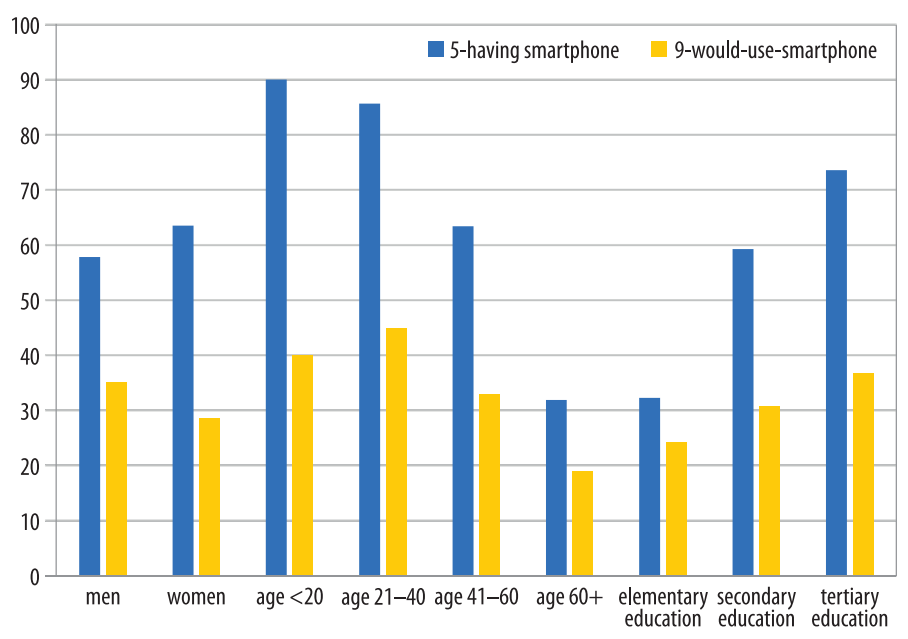

Fig. 2. Share of respondents having/willing to use a smartphone for navigation in the hospital according to gender, age, and education, in per cent. Source: Author's own survey. ed, so their real numbers might be different). More interestingly, the share of patients/ visitors refusing to use a smart navigational app is high in all age groups. A positive association between educational level and acceptance of the SmartApp has been found.

The most perceived wayfinding difficulties differed significantly among particular pavilions and departments of the hospital (Table 2, Figure 3). Almost half of the answers that the hospital department was rather difficult to find were concentrated in pavilion I, the most remote building from the gateway. Contrary to our expectations, women's perceived wayfinding difficulties were not more spatially concentrated at the level of buildings compared to men. Gender differences in the perception of particular pavilions were rather minor and did not show any systematic pattern. Surprisingly, neither the elderly nor less educated people showed systematically higher perceived wayfinding difficulties than younger and more educated respondents. Perceived wayfinding difficulties of people with elementary education were more spatially uneven than in the case of more educated respondents.

Most of the abovementioned spatial differences in perceived wayfinding difficulties appear to be statistically significant (Table 3). These findings apply both for men and women, age groups 21-40 and 41-60, and people with secondary and tertiary education. On the other hand, significant differences in wayfinding among particular pavilions were found neither for people with elementary education nor for the age group $60+$. The latter can be explained by more frequent visits to the hospital complex by the elderly. However, the expected gender, age, and education differences were 
Table 2. Share of the hospital pavilions in the total number of answers*, in per cent

\begin{tabular}{l|c|c|c|c|c|c|c|c|c|c|c}
\hline Variable name & A & B & D & E & F & H1 & H2 & H3 & I & HHI \\
\hline Men & 0.0 & 0.1 & 6.8 & 5.1 & 14.7 & 0.3 & 23.8 & 0.8 & 48.5 & 1,984 \\
\hline Women & 0.1 & 0.4 & 6.9 & 6.9 & 19.2 & 0.8 & 14.0 & 1.3 & 47.4 & 1,786 \\
\hline \multicolumn{10}{|c|}{ Age, years } \\
\hline $21-40$ & - & 33.3 & 75.0 & 39.1 & 29.7 & 50.0 & 38.7 & 42.9 & 35.6 & 2,437 \\
\hline $41-60$ & 7.7 & 60.0 & 70.0 & 25.0 & 43.5 & 35.7 & 24.4 & 29.4 & 46.1 & 1,875 \\
\hline $60+$ & 22.2 & 25.0 & 33.3 & 36.4 & 28.4 & 30.0 & 25.4 & 22.2 & 40.4 & 2,013 \\
\hline \multicolumn{8}{|c|}{} & \multicolumn{10}{|c|}{ Education } \\
\hline Elementary & 2.4 & 4.1 & 2.4 & 8.9 & 18.7 & 0.8 & 35.0 & 2.4 & 25.2 & 2,322 \\
\hline Secondary & 1.8 & 1.9 & 5.4 & 11.0 & 19.2 & 3.2 & 25.4 & 5.4 & 26.1 & 1,894 \\
\hline Tertiary & 4.6 & 1.7 & 12.1 & 14.9 & 14.9 & 3.4 & 14.9 & 2.9 & 30.5 & 1,788 \\
\hline
\end{tabular}

${ }^{*}$ Answers for the whole hospital, that the patients/visitors had difficulty with finding the place. A-I are signs of hospital pavilions, HHI = Herfindahl-Hirschmann index. Source: Authors' own survey.

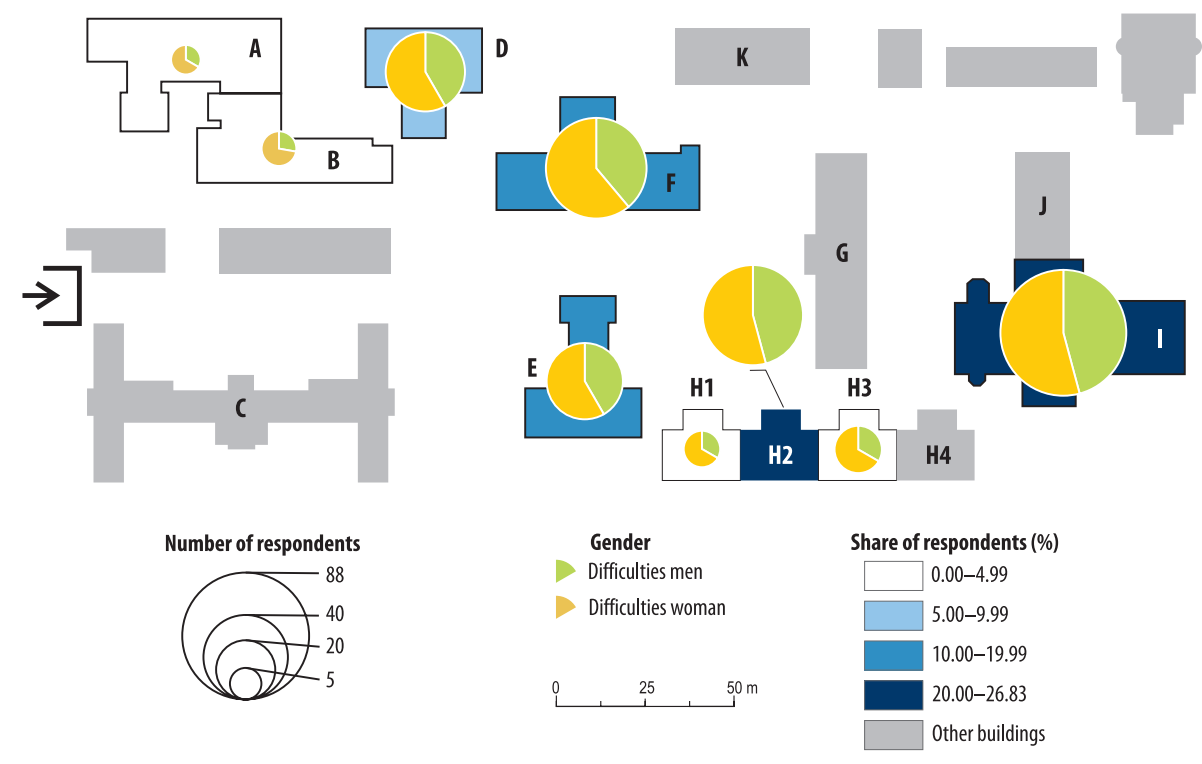

Fig. 3. Spatial distribution of perceived wayfinding difficulties in the hospital complex. Source: Author's own survey.

not found. Women, elderly and less educated people do not show higher spatial differences in wayfinding than men, younger and more educated respondents.
More importantly, substantial spatial differences were found also in the rate of SmartApp acceptance. Significant effects of the variable Location on the intention to use a smartphone 
Table 3. Spatial differences in perceived wayfinding difficulties and the SmartApp acceptance

\begin{tabular}{l|c|c|c|c|c|c}
\hline \multirow{2}{*}{$\begin{array}{c}\text { Variable } \\
\text { name }\end{array}$} & \multicolumn{5}{c}{ Location X } \\
\cline { 2 - 7 } & $\mathrm{N}$ & $\mathrm{V}$ & $\mathrm{p}$ & $\mathrm{N}$ & $\mathrm{V}$ & $\mathrm{p}$ \\
\cline { 2 - 6 } & \multicolumn{5}{c}{ Wayfinding difficulties } & Gender \\
\hline Men & 384 & 0.251 & $<0.001$ & 382 & 0.188 & 0.095 \\
\hline Women & 199 & 0.199 & 0.020 & 478 & 0.200 & 0.006 \\
\hline \multicolumn{7}{|c}{ Age, years } \\
\hline $21-40$ & 185 & 0.267 & 0.049 & 186 & 0.207 & 0.461 \\
\hline $41-60$ & 341 & 0.296 & $<0.001$ & 342 & 0.172 & 0.454 \\
\hline $60+$ & 318 & 0.136 & 0.982 & 317 & 0.254 & 0.005 \\
\hline \multicolumn{7}{|c|}{ Education } \\
\hline Elementary & 115 & 0.271 & 0.663 & 117 & 0.373 & 0.017 \\
\hline Secondary & 588 & 0.177 & 0.024 & 587 & 0.162 & 0.062 \\
\hline Tertiary & 159 & 0.424 & $<0.001$ & 159 & 0.276 & 0.108 \\
\hline
\end{tabular}

Source: Authors' own survey.

for navigation were found in the group of men, women, seniors $60+$, and people with elementary education. While not strong, there is a positive association between perceived wayfinding difficulties and SmartApp acceptance at the level of hospital pavilions. Respondents in the difficult-to-find pavilions and departments were generally more keen to use a smartphone for navigation.

In the next step, we tested the effects of gender, age, education, and location on SmartApp acceptance (Table 4). We constructed many combinations of regression models, including also all other explanatory variables listed in Table 1. These variables, however, did not increase the explanatory power of the model substantially or show a significant effect on the dependent variables. After all pre-tests, we decided to keep the model as simple as possible, including only the variables Gender, Age, Education, Location and interaction of gender, and age (following VeNKatesh, V. et al. 2012) as the explanatory variables. The dependent variable was dichotomous: intention to use a smartphone application for navigation in the hospital: SmartApp acceptance (yes or no).

Education showed the strongest positive association with the dependent variable: the intention to use a smart application for navi- gation in the hospital is highest in the group of people with tertiary education. While statistically significant, there were no major differences between men and women: men showed only slightly higher rates of technology acceptance. The model explained a relatively low share of the variability of the dependent variables (16.1\%). SmartApp acceptance decreases with rising age; it is significantly lower in the age group 60+. The spatial variable pavilion showed the second strongest effect, reflecting the high share of the remote pavilion in the total number of perceived wayfinding difficulties.

\section{Discussion}

We found no major gender gap in the intention to use smart apps for navigation in the hospital: in accordance with Hwang, K.H. et al. (2016), or Silber-VArod, V. et al. (2019). This contrasts with the traditional digital divide model (RicE, R.E. and Katz, J.E. 2003), which favours males and their higher willingness to use new technologies and overcome the associated difficulties with their adoption. While many respondents (especially the elderly ones) may have no experience with the use of navigation smart apps, these 
Table 4. Correlates of patient and visitor acceptance of a smart navigation app

\begin{tabular}{l|c|c|c|c|c|c}
\hline \multicolumn{7}{c}{ Variables in the Equation } \\
\hline \multicolumn{1}{c}{ Step 1* } & B & S.E. & Wald & df & Sig. & Exp(B) \\
\hline N11_Gender(1) & -0.385 & 0.194 & 3.929 & 1 & 0.047 & 0.680 \\
N12_Age & - & - & 51.456 & 3 & 0.000 & - \\
N12_Age(1) & -3.439 & 1.070 & 10.334 & 1 & 0.001 & 0.032 \\
N12_Age(2) & -1.859 & 0.299 & 38.660 & 1 & 0.000 & 0.156 \\
N12_Age(3) & -0.963 & 0.194 & 24.702 & 1 & 0.000 & 0.382 \\
N13_Education & - & - & 6.866 & 2 & 0.032 & - \\
N13_Education(1) & 0.715 & 0.032 & 4.647 & 1 & 0.031 & 2.043 \\
N13_Education(2) & 0.017 & 0.240 & 0.005 & 1 & 0.942 & 1.017 \\
Age_Gender & - & - & 0.045 & 1 & 0.832 & - \\
Age_Gender(1) & -0.096 & 0.453 & 0.045 & 1 & 0.832 & 0.908 \\
Location & - & - & 4.812 & 3 & 0.186 & - \\
Location(1) & 0.137 & 0.265 & 0.267 & 1 & 0.605 & 1.147 \\
Location(2) & 0.297 & 0.236 & 1.582 & 1 & 0.208 & 1.346 \\
Location(3) & 0.483 & 0.229 & 4.472 & 1 & 0.034 & 1.622 \\
Constant & 0.637 & 0.316 & 4.055 & 1 & 0.044 & 1.891 \\
\hline
\end{tabular}

*Variable(s) entered on step 1: N11_Gender, N12_Age, N13_Education, Age-Gender, Section_AGR_reduced. -2 Loglikelihood $=805.946 ;$ Cox\&Snell R Square $=0.161$; Nagelkerke R Square $=0.215$. Source: Authors' own survey .

technologies are currently not in the early stage of development. Therefore, perceived ease of use - while generally an important predictor of technology acceptance (DAvis, F.D. et al. 1989; Menra, A. et al. 2020) is probably not a key factor affecting the willingness to use smart navigation apps (ARNING, K. et al. 2012). Gender differences in some spatial abilities favouring men (GALEA, L.A.M. and Kimura, D. 1993; Lawton, C.A. 2001) and higher spatial anxiety/uncertainty of women in the real environment (LawTON, C.A. et al. 1996; Mendez-Lopez, M. et al. 2020) do not translate into higher demand for smart navigation apps among women (ŽENKA, J. et al. 2021). We, thus, do not confirm the assumption that people who are good at navigating themselves are not in an urgent need to use an indoor navigation system and may be less willing to adopt a smart indoor navigation system (SMirnov, M. 2007; Wichmann, J. and LEYER, M. 2021).

Age was by far the most important factor of technology acceptance, confirming the findings of RicE, R.E. and KATZ, J.E. (2003). Technology acceptance decreases with increasing age (Olson, K.E. et al. 2011), which was clearly supported also for the case of smart navigation apps in the hospital.
Statistical tests of the interactions between age and gender and education showed nonsignificant results. This is probably caused by the limited number of answers, when disaggregated according to the age/education category and gender, despite using the broadest possible age categories (less than 40 and $40+$ ).

Despite nonsignificant results in the regression models, the interaction between gender and age has effects on the dependent variable: younger males are the most willing to use smart navigation apps, $40+$ women the least. Interestingly, gender differences between the younger respondents are much higher than between the 40+ respondents. Therefore, our results contrast sharply with the conclusions of Morris, M.G. et al. (2005, 79), who stated that “...gender differences decline dramatically among the younger cohort of workers and a more unisex pattern emerges". We agree with the statement "mobile service adoption and usage may vary significantly among young users, thus, treating them as a homogeneous group is not appropriate" (RAO, S. and Troshani, I. 2007, 68). Smaller gender differences between the $40+$ respondents - more frequent visitors to the hospital - may be caused by their higher familiarity with the hospital complex 
and perhaps also by generally higher selfconfidence in spatial abilities compared to younger people (De BeNI, R. et al. 2006). In addition, elderly men tend to rely more on established habits, so their technology acceptance is lower compared to younger men (Venkatesh, V. et al. 2012).

We found positive effects of education on the SmartApp acceptance in the hospital. In this case, the formal educational level should be viewed as a proxy of general cognitive abilities (see EliAs, M.F. et al. 1997, or Le Carret, N. et al. 2003), spatial abilities (Proust-Lima, C. et al. 2008; Ulrich, S. et al. 2019), and an intention to gain new (technical) skills. Arning, K. et al. (2012) argue that smart navigation technology acceptance is affected by the level of individual technical self-efficacy (TSE), defined as the confidence in one's own ability to solve technical problems. Wichmann, J. and Leyer, M. (2021), on the other hand, found no significant effects of perceived behavioural control, operationalized as the individual perception of own control and the ability to use applications for indoor navigation. Even more importantly, these authors also documented the negative effects of individual spatial abilities on the intention of visitors/patients to adopt an indoor navigation and localization system in the hospital. Our results, however, support the assumption that cognitive abilities, represented in our model of formal education, increase the acceptance of smart navigation technologies. This effect is stronger for younger respondents.

We did not find empirical evidence for our initial assumption that perceived wayfinding difficulties will be more spatially concentrated in the case of women, the elderly, and people with elementary education compared to men, younger and more educated respondents. Principal differences in spatial abilities and orientation strategies (LAWTON, C.A. 1994) between men (cardinal directions) and women (landmarks), younger and older (less and more educated) people do not result in significant variations in perceived wayfinding difficulties among the pavilions in the hospital complex. On the other hand, significant spatial differences were found not only in perceived wayfinding difficulties, but also in the intention to use a smart navigation application. The latter finding corresponds with the conclusion of ARNing, K. et al. (2012) that disorientation is the most powerful predictor of navigation device acceptance.

\section{Conclusions}

The main aim of this paper was to determine if hospital patients/visitors intend to use a mobile navigation application. To answer these questions, we conducted a questionnaire survey among 928 respondents in the Vítkovice Hospital in Ostrava, Czechia. Despite the high share of elderly and regular visitors, almost 70 per cent of respondents answered that they accept a smart navigation app in the hospital. We tested the effects of age, gender, education, and location in the hospital complex on individual acceptance of the smart navigation app. Age was the key factor of technology acceptance, which was found to be the lowest in the group of $60+$ respondents. Education showed a strong and positive effect on SmartApp acceptance, which was highest among respondents with tertiary education.

No major gender gap in technology acceptance was observed, which supports the previous findings of ŽEnKA, J. et al. (2021). The assumptions of the unified theory of technological acceptance that gender differences are more pronounced in older age groups were, thus, not supported by empirical evidence. On the contrary, respondents 40+ were more homogeneous in their answers than their younger counterparts, while men below 40 were much more willing to use the smart navigation app than women in the same age group. The higher homogeneity of the 40+ age group might be explained by the familiarity of many (especially elderly) respondents with the hospital complex be- 
cause they are relatively frequent visitors of the Vítkovice Hospital complex.

Finally, the location was another major factor of perceived wayfinding difficulties and SmartApp acceptance for navigation in the hospital. We confirmed the finding of ArNing, K. et al. (2012) that disorientation is a strong determinant of navigation device acceptance. On the other hand, we did not get sufficient empirical evidence for our assumption that general gender/age/educational differences in spatial abilities and navigational strategies translate into the specific spatial pattern of perceived wayfinding difficulties and technology acceptance in the hospital complex. There were no major and systematic gender/age/educational differences among particular hospital locations (pavilions, departments). Surprisingly, in the group of people $60+$ relatively small variations in perceived wayfinding difficulties among the hospital pavilion/departments were found. This could be explained by relatively frequent visits and, thus, a high familiarity with the hospital complex.

Future research on technology acceptance should develop a further link between the spatial factors and the intention to use a smart navigation device. Empirical evidence shows that disorientation in complex buildings and compounds increases people's acceptance of smart navigational devices. However, little is known about the mechanisms and interactions with other nonspatial factors, such as gender, age, and individual cognitive abilities.

If we turn to some practical implications of our research, the findings suggest the importance of efficient navigational cues located near the entrance to the hospital complex. The perceived wayfinding difficulties of respondents were spatially concentrated mostly in the most remote pavilion in the hospital complex, which is obscured by other buildings. Therefore, differences among other pavilions/departments in landmarks and other navigational cues were of minor importance. A key factor for wayfinding success was the ability to form a cognitive map of the whole hospital complex. In small hospitals, the navigational system should focus on cardinal directions and the presentation of the entire hospital complex.

Acknowledgements: This research was founded by the Ministry of Education, Youth and Sports through a research grant ú SMART technologies to improve the quality of life in cities and regions (no. CZ.02.1.01/0.0/0.0/17_049/000 8452).

\section{REFERENCES}

AGEL 2020. International sources of the Vitkovice Hospital.

Ajzen, I. 1991. The theory of planned behavior. Organizational Behavior and Human Decision Processes 50. (2): 179-211.

Anacta, V.J.A. and Schwering, A. 2010. Men to the east and women to the right: Wayfinding with verbal route instructions. In Spatial Cognition VII. Lecture Notes in Computer Science Vol. 6222 Eds.: Hölscher, C., Shipley, T.F., Olivetti Belardinelli, M., Bateman, J.A. and Newcombe, N.S., Berlin-Heidelberg, Springer Verlag, 70-84. Available at https://doi.org/10.1007/978-3-64214749-4_9

Anagnostopoulos, G.G., Deriaz, M., Gaspoz, J.M., Konstantas, D. and Guessous, I. 2017. Navigational needs and requirements of hospital staff: Geneva University hospitals case study. In Proceedings of International Conference on Indoor Positioning and Indoor Navigation, IPIN. 18-21 September 2017. Sapporo, Japan. 1-8. Doi:10.1109/IPIN.2017.8115958

Arning, K., Ziefle, M., LI, M. and Kobbelt, L. 2012. Insights into user experiences and acceptance of mobile indoor navigation devices. In Proceedings of the $11^{\text {th }}$ International Conference on Mobile and Ubiquitous Multimedia. New York, Association for Computing Machinery, 1-10. Doi:10.1145/2406367.2406417

Balata, J., Macik, M. and Miкovec, Z. 2013. Context sensitive navigation in hospitals. Paper for MobileMed 2013: Conference on Mobile and Information Technologies in Medicine. 20 November, 3013. Prague, Czech republic. Available at https://www. researchgate.net/publication/258705738_Context Sensitive_Navigation_in_Hospitals

Brown, M., Pinchin, J., Valand, R., Larkin, C., Pattinson, J., Benning, K., Housley, G., Hatton, J., Shaw, D., Syrysko, P., Sharples, S. and Blakey, J.D 2016. NightShift simulation to train newly qualified doctors in non-technical skills: a feasibility study. Future Hospital Journal 3. (2): 94-98.

Calderoni, L., Ferrara, M., Franco, A. and Maio, D. 2015. Indoor localization in a hospital environment 
using Random Forest classifiers. Expert Systems with Applications 42. (1): 125-134.

Coluccia, E. and Louse, G. 2004. Gender differences in spatial orientation: a review. Journal of Environmental Psychology 24. 329-340.

Custodio, R., Gard, A.M., Graham, G., Satariano, W.A., Scharlach, A.E., Lindeman, D., Plude, D.J. and Hoyer, W.J. 1986. Age and the selectivity of visual information processing. Journal of Psychology and Aging 1. (1): 4-10.

Davies, C. and Pederson, E. 2001. Grid patterns and cultural expectations in urban wayfinding. In Spatial Information Theory: Foundations of Geographic Information Science. Proceedings. Ed.: MonTello, D.R., Berlin-Heidelberg, Springer Verlag, 400-414.

Davis, F.D., Bagozzi, R.P. and Warshaw, P.R. 1989. User acceptance of computer technology: A comparison of two theoretical models. Management Science 35. (8): 982-1003.

De Beni, R., Pazzaglia, F. and Gardini, S. 2006. The role of mental rotation and age in spatial perspective-taking tasks: when age does not impair perspective-taking performance. Applied Cognitive Psychology 20. (6): 807-821.

DevLIN, A.S. 2014. Wayfinding in healthcare facilities: Contributions from environmental psychology. Behavioral Sciences 4. (4): 423-436.

Elias, M.F., Elias, P. K., D'Agostino, R.B., Silbershatz, H. and Wolf, P.A. 1997. Role of age, education, and gender on cognitive performance in the framingham heart study: Community-based norms. Experimental Aging Research 23. (3): 201-235.

Galea, L.A.M. and Kimura, D. 1993. Sex differences in route-learning. Personality and Individual Differences 14. (1): 53-65.

Harris, M.A. and Wolberts, T. 2014. How age-related strategy switching deficits affect wayfinding in complex environments. Neurobiology of Aging 35. (5): 1095-1102.

Harwood, J. 2007. Understanding Communication and Aging: Developing Knowledge and Awareness. Newbury Park, CA, USA, SAGE Publications.

Hölscher, C., Meilinger, T., Vrachliotis, G., Brösamle, M. and Knauf, M. 2006. Up the down staircase: Wayfinding strategies in multi-level buildings. Journal of Environmental Psychology 26. (4): 284-299.

Hwang, K.H., Chan-Olmsted, S.M., Nam, S.H. and CHANG, B.H. 2016. Factors affecting mobile application usage: Exploring the roles of gender, age, and application types from behaviour log data. International Journal of Mobile Communications 4. (3): 256-272.

Iaria, G., Palermo, L., Committeri, G. and Barton, J.J.S. 2009. Age differences in the formation and use of cognitive maps. Behavioural Brain Research 196. (2): 187-191.
Lapon, L., Ooms, K., De Wit, B., Vanhaeren, N. and De MAeYer, P. 2020. People's global-scale cognitive map versus their personal characteristics: a worldwide study. Cartography and Geographic Information Science 47. (6): 765-779.

Lawton, C.A. 1994. Gender differences in way-findig strategies: Relationship to spatial ability and spatial anxiety. Sex Roles 30. (11-12): 321-337.

Lawton, C.A. 2001. Gender and regional differences in spatial referents used in direction giving. Sex Roles 44. (5-6): 321-337.

Lawton, C.A., Charleston, S.I. and Zieles, A.S. 1996. Individual- and gender-related differences in indoor wayfinding. Environment and Behavior 2. (28): 204-219.

Le Carret, N., Lafont, S., Letenneur, L., Dartigues, J.F., Mayo, W. and Fabrigoule, C. 2003. The effect of education on cognitive performances and its implication for the constitution of the cognitive reserve. Developmental Neuropsychology 23. (3): 317-337.

Liao, H. and Dong, W. 2017. An exploratory study investigating gender effects on using $3 \mathrm{D}$ maps for spatial orientation in wayfinding. ISPRS International Journal of Geo-Information 6. (3): 60. Available at https://doi.org/10.3390/ijgi6030060

Lynnot, P.P. and McCandless, J. 2000. The impact of age vs. life experience on the gender role attitudes of women in different cohorts. Journal of Women $\mathcal{E}$ Aging 12. (1): 5-21.

Mehra, A., Paul, J. and Kaurav, R.P.S. 2020. Determinants of mobile apps adoption among young adults: theoretical extension and analysis. Journal of Marketing Communications 2020. Online publication, 1-29. Available at https://doi.org/10.1080/13527266 .2020 .1725780

Mendez-Lopez, M., Fidalgo, C., Osma, J. and Juan, M.C. 2020. Wayfinding strategy and gender - Testing the personality and emotions. Psychology Research and Behavior Management 13. 119-131.

Mollerup, P. 2009. Wayshowing in hospital. Australasian Medical Journal 2. (10): 112-114.

Morris, M.G., VenKatesh, V. and Ackerman, P.L. 2005. Gender and age differences in employee decisions about new technology: An extension to the theory of planned behavior. IEEE Transactions on Engineering Management 52. (1): 69-84.

Newman, M.C. and KaszniaK, A.W. 2000. Spatial memory and aging: Performance on a human analog of the Morris water maze. Aging, Neuropsychololy and Cognition 7. (2): 86-93.

Olson, K.E., O'Brien, M.A., Rogers, W.A. and Charness, N. 2011. Diffusion of technology: Frequency of use for younger and older adults. Ageing International 36. (1): 123-145.

Posner, R.A. 1997. Aging and Old Age. Chicago, University of Chicago Press.

Proust-Lima, C., Amieva, H., Letenneur, L., Orgogozo, J.M., Jacqmin-Gadda, H. and Dartigues, J.F. 2008. 
Gender and education impact on brain aging: A general cognitive factor approach. Psychology and Aging 23. (3): 608-620.

Rao, S. and Troshani, I. 2007. A conceptual framework and propositions for the acceptance of mobile services. Journal of Theoretical and Applied Electronic Commerce Research 2. (2): 61-73.

Rice, R.E. and Katz, J.E. 2003. Comparing internet and mobile phone usage: Digital divides of usage, adoption, and dropouts. Telecommunications Policy 27. (8-9): 597-623.

Rodgers, M.K., Sindone, J.A. and Moffat, S.D. 2012. Effects of age on navigation strategy. Neurobiology of Aging 1. (33): 202.e15-202.e22.

Silber-Varod, V., Blau, I. and Lis-Hacohen, R. 2019. Gender in shared navigation: Men to Mars, women to Venus? Journal of Computer Information Systems 59. (2): 171-177.

Smirnov, M. 2007. Spatial Information Theory. BerlinHeidelberg, Springer.

SouzA, R.F. and Martins, L.B. 2019. Wayfinding of people with disability and reduced mobility in the urban space. In Studies in Systems, Decision and Control. Series ed.: KАсрRzүк, J., Berlin, Springer International Publishing, 775-783.

Ulrich, S., Grill, E. and Flanagin, V.L. 2019. Who gets lost and why: A representative cross-sectional survey on sociodemographic and vestibular determinants of wayfinding strategies. PLOS ONE 14. (1): 1-16.
Venkatesh, V., Morris, M.G., Davis, G.B. and Davis, F.D. 2003. User acceptance of information technology: Toward a unified view. MIS Quarterly 27. (3): 425-458.

Venkatesh, V., Thong, J. and Xu, X. 2012. Consumer acceptance and use of information technology: Extending the unified theory of acceptance and use of technology. MIS Quarterly 36. (1): 157-178.

Wichmann, J. and Leyer, M. 2021. Why do Visitors intend to use Indoor Navigation and Indoor Localization Systems in Hospitals? A Quantitative Survey from Germany. In Proceedings of the $54^{\text {th }}$ Hawaii International Conference on System Sciences. Online publication, 3694-3703. Doi:10.24251/ HICSS.2021.447

Wolstenholme, D., Совb, M., Bowen, S., Wright, P.C. and Dearden, A. 2010. Design led service improvement for older people. Australasian Medical Journal AMJ 3. 465-470.

Ženka, J., Macháčé, J., Michna, P. and Kořizek, P. 2021. Navigational needs and preferences of hospital patients and visitors: What prospects for smart technologies? International Journal of Environmental Research and Public Health 18. (3): 1-20. 
